\title{
Early Sensitivity to Sound and Musical Preferences and Enjoyment in Adolescents With Autism Spectrum Disorders
}

\author{
Anjali Bhatara \\ McGill University
}

\author{
Eve-Marie Quintin \\ McGill University and Université du Québec à Montréal
}

\author{
Eric Fombonne and Daniel J. Levitin \\ McGill University
}

\begin{abstract}
Children with autism spectrum disorders (ASD) frequently display unusual reactions to sound, ranging from idiosyncratic responses to avoidances. This atypical sensitivity often decreases over time, but little is known about how early avoidance of sounds might affect later enjoyment of auditory stimuli such as music. We surveyed children and adolescents with ASD, and an age-matched group of typically developing (TD) adolescents and the parents of both groups about early auditory sensitivities and musical experience, preferences, and enjoyment in later childhood and adolescence using an adaptation of the Queen's University Music Questionnaire and the Salk and McGill Musical Inventory (SAMMI). Results showed that, although the group with ASD experienced much more auditory hypersensitivity than the TD group during childhood, there were no differences between groups in musical ability, memory, reproduction, creativity, or interest and emotional responsivity to music in later childhood and adolescence; both groups displayed a similar variety of genres in their musical preferences, with the exception that more participants with ASD reported classical as their favorite musical genre. We suggest that this latter pattern may arise from their lesser use of music as a mark of social affiliation and peer-group bonding, or from the increased complexity of classical music relative to other genres. We conclude that early childhood hypersensitivities to sound do not have detrimental effects on later enjoyment of music, although children and adolescents with ASD may use music in ways that differ from their TD peers.
\end{abstract}

Keywords: auditory sensitivity, music perception, adolescence, autism spectrum disorders

Supplemental materials: http://dx.doi.org/10.1037/a0033754.supp

Shared music preference and enjoyment promote social cohesiveness within typical adolescent peer groups (North \& Hargreaves, 1999; North, Hargreaves, \& O'Neill, 2000; Selfhout, Branje, ter Bogtb, \& Meeus, 2009). The role of music in the lives of adolescents with autism spectrum disorders (ASD) is less well understood. If the promotion of social cohesiveness is an important factor in adolescents' music listening choices and behaviors, then adolescents with ASD, who show impairments in social and communicative abilities (American Psychiatric Association, 2000), might show patterns of listening that are different from those of typically developing (TD) adolescents. However, it is also possible that adolescents with ASD will show no difference from TD adolescents in their musical preferences and listening habits or that they will show less enjoyment of music than do TD adolescents, as hypothesized by Peretz (2001).

At present, a lack of research on musical preferences in adolescents with ASD prevents the formation of strong hypotheses in one direction or the other. Thus, the first goal of the present study is to examine this question by collecting data on music listening habits, musical preferences, and formal musical experience of children and adolescents with ASD (hereafter referred to as "adolescents" for brevity). Investigating the role of music in the everyday life of
Anjali Bhatara, Department of Psychology, McGill University, Montreal, Quebec, Canada; Eve-Marie Quintin, Department of Psychology, McGill University, and Department of Psychology, Université du Québec à Montréal, Montreal, Quebec, Canada; Eric Fombonne, Department of Psychiatry and Montreal Children's Hospital, McGill University; Daniel J. Levitin, Department of Psychology, McGill University.

Authors Anjali Bhatara and Eve-Marie Quintin contributed equally to this work.

We thank the participants and their families; the English Montreal Schoolboard, Summit School, Montreal Children's Hospital; Annie Coulter, Shirley Elliott, and Bianca Levy for help with recruitment and assessments. The research was supported in part by a doctoral grant to
EMQ by FQRSC and the Canadian Autism Research Training Program (funded by CIHR) and by research grants to DJL from NAAR (now Autism Speaks) and NSERC.

Photos and brief biographies of the authors are available at http:// dx.doi.org/10.1037/a0033754.supp

Correspondence concerning this article should be addressed to EveMarie Quintin, Center for Interdisciplinary Brain Sciences Research, Stanford University, 401 Quarry Road, Palo Alto, CA 94305. E-mail: evemariequintin@gmail.com or quintin@stanford.edu OR Anjali Bhatara, Laboratoire Psychologie de la Perception, CNRS, Université Paris Descartes, 45 rue des Saints-Pères, 75006 Paris, France. E-mail:bhatara@gmail.com 
individuals with ASD will help to translate results from the growing research on music and ASD to development and improvement of music-based treatments.

Individuals with ASD often demonstrate hypersensitivity to sound (Levitin et al., 2004; Stiegler \& Davis, 2010), which may also influence their musical preferences. Auditory hypersensitivity is prevalent in early childhood in ASD, during a time when musical preferences are likely developing, and it tends to become less severe with maturity (Baranek, Parham, \& Bodfish, 2005). Auditory hypersensitivity in early childhood could have the effect of reducing tolerance to any type of sound, in turn reducing the time a child would choose to spend listening to or playing music. Alternatively, hypersensitivity to sound could increase the child's enjoyment of the music, causing him or her to spend more time listening to and playing music. The second aim of this study is thus to examine the history of auditory sensitivity of adolescents with ASD and the relation between this sensitivity and music listening habits, musical preferences, and formal musical experience.

There are several factors in addition to auditory hypersensitivity that may influence music listening habits and preferences. Relevant research describing these factors, which include atypicalities of the auditory system, pitch processing, and recognition of emotion in music, are discussed in the following sections.

\section{Auditory Hypersensitivity}

Unusual sensory features or reactions to sensory stimulation are often observed in individuals with ASD, especially during early childhood (Baranek et al., 2005). Enhanced sensitivity to sounds was reported in the first account of ASD (Kanner, 1943). There are several ways of investigating auditory function. First, in tests of hearing thresholds, some studies and reviews have reported a greater-than-normal prevalence of hearing loss (Klin, 1993; Rosenhall, Nordin, Sandström, Ahlsén, \& Gillberg, 1999) as well as increased rates of ear infections and other otological abnormalities (Chin, Moran, \& Fenton, 2013; Konstantareas \& Homatidis, 1987) whereas other studies have shown no difference in ear physiology measurements between groups with ASD and TD controls (Gravel, Dunn, Lee, \& Ellis, 2006; Tharpe et al., 2006). Note, however, that Gravel et al. (2006) excluded two adolescents from the ASD group because of hearing loss or atypical middle ear function, and Tharpe et al. (2006) found elevated hearing thresholds in the ASD group even though their physiological measurements were normal.

Leekam, Nieto, Libby, Wing, and Gould (2007) observed that $90 \%$ of study participants with ASD had sensory abnormalities in one or more domains. In a commonly used self- or parent-report measure of sensory sensitivities, the Short Sensory Profile (Dunn, 1999), young children with ASD frequently show abnormalities in "Auditory filtering" (Rogers, Hepburn, \& Wehner, 2003; Tomchek \& Dunn, 2007; Wiggins, Robins, Bakeman, \& Adamson, 2009), defined as the ability to use and screen out sounds in daily life (McIntosh, Miller, \& Shyu, 1999). Individuals with ASD often report hyperacusis (Rimland \& Edelson, 1995), with varying rates depending on study methodology (Baranek, Boyd, Poe, David, \& Watson, 2007). The definition and use of the term "hyperacusis" is inconsistent in the literature (Khalfa et al., 2000; Levitin, Cole,
Lincoln, \& Bellugi, 2005). However, many authors investigating hyperacusis in ASD define it as a marked intolerance or hyperreactivity to sounds that are neither too loud nor uncomfortable for most people (Alcántara, Weisblatt, Moore, \& Bolton, 2004; Bettison, 1996; Kulesza \& Mangunay, 2008; Stiegler \& Davis, 2010). In addition, loudness judgments exhibited by children and adolescents with ASD suggest that many are in fact more sensitive to loud sounds than are TD controls (Khalfa et al., 2004). Parental reports also indicate that children with ASD give responses associated with pain, fright, or distress more frequently than TD children when they hear certain sounds (Levitin et al., 2005; Tharpe et al., 2006). Various interventions, such as systematic desensitization and reward systems, have been shown to help children with ASD tolerate these sounds (Stiegler \& Davis, 2010).

Although the causes of hyperacusis or hypersensitivity to sound are not known, there exists evidence of abnormalities at multiple levels within the auditory system of individuals with ASD. For example, a psychophysical study showed abnormally wide auditory filters in the group with ASD (Plaisted, Saksida, Alcántara, \& Weisblatt, 2003), and EEG and MEG studies have shown atypical brainstem responses (Rosenhall, Nordin, Brantberg, \& Gillberg, 2003; Russo et al., 2008) or cortical auditory responses among individuals with ASD (Bomba \& Pang, 2004; Bruneau, BonnetBrilhault, Gomot, Adrien, \& Barthélémy, 2003; Gage, Siegel, Callen, \& Roberts, 2003; Gage, Siegel, \& Roberts, 2003; Gomot et al., 2011).

\section{Pitch Processing in ASD}

Several studies have shown individuals with ASD to have enhanced pitch processing abilities. Compared with TD children, children with ASD can segregate notes within musical chords more accurately (Heaton, 2003, 2005), and children and young adults with ASD detect contour-preserving alterations of single notes in a melody more accurately (Mottron, Peretz, \& Ménard, 2000). Individuals with ASD also show enhanced pitch discrimination abilities in some contexts (Bonnel et al., 2003, 2010), but recent evidence suggests that they may in fact be impaired in pitch discrimination at higher frequencies (Bhatara, Babikian, Laugeson, Tachdjian, \& Sininger, 2013).

\section{Perception of Emotion in Music}

For adults who do not have ASD, one of the main functions of music in daily life is to change or enhance one's mood (Sloboda \& O'Neill, 2001). Survey results from North et al. (2000) led the authors to conclude that music is important in the lives of adolescents for two main reasons: (a) it allows them to portray an image to outsiders and (b) it satisfies emotional needs. The first reason is less likely to be of importance for adolescents with ASD who are generally both less interested in and less adept at portraying a particular image to their peers. However, they may listen to music to satisfy emotional needs. Allen, Hill, and Heaton (2009) found that adults with ASD listen to music to alter or induce states of arousal. Further, there exists evidence that the ability to categorize musical emotions is preserved in ASD. Heaton, Hermelin, and Pring (1999) found that children with ASD can associate melodies in a major mode to schematic depictions of a happy face and melodies in a minor mode to schematic depictions of a sad face. 
Children with ASD were also unimpaired (relative to verbal mental age-matched controls) in associating musical excerpts conveying emotions and mental states such as anger, fear, love, triumph, and contemplation to visual illustrations of these emotional states (Heaton, Allen, Williams, Cummins, \& Happé, 2008). Quintin, Bhatara, Poissant, Fombonne, and Levitin (2011) found that adolescents with high-functioning ASD could associate happy, sad, scary, and peaceful music to schematic faces as accurately as controls when accounting for verbal ability. Their ratings of emotional intensity did not differ from controls. However, ratings of musical expressivity, associated with variations of timing and amplitude in musical compositions, were found to differ between adolescents with ASD and TD controls (Bhatara et al., 2010). Thus, categorization of musical emotions does not seem to be impaired in ASD, whereas perception of subtle expressive musical cues requires further study. In addition, Allen, Davis, and Hill (2013) showed that emotional responsivity to music is unimpaired in high-functioning adults with ASD, although they may demonstrate difficulty verbalizing these responses (before controlling for alexithymia). There is also preliminary evidence that people with low-functioning ASD show a preference for familiar music over environmental sounds and for pleasant (consonant) over unpleasant (dissonant) music (Boso, Comelli, Vecchi, Barale, \& Politi, 2009). Allen et al. (2009) found that adults with ASD frequently use music in everyday life but that they tend to describe the effects of listening differently than what is usually reported by the general population, that is, they used more words describing states of arousal rather than mood or valence. They also showed that almost half of their participants with ASD reported a preference for classical music, and that this preference had developed during childhood.

In sum, there is growing evidence that individuals with ASD display enhanced sensitivity to sounds alongside unimpaired perception of many aspects of music processing, including recognizing basic musical emotions. Although an increasing interest in music perception in ASD has fueled studies over the past decade, most studies have assessed performance of participants with ASD on laboratory tasks (with the exception of a few studies such as that by Allen et al., 2009). Thus, the present study uses questionnaires to assess musical habits in adolescents with ASD and TD control participants in everyday life. We evaluate whether the groups differ on various measures such as formal musical training, time spent listening to music, music genre preferences, and reported interest in music. Furthermore, information on sensitivity to sounds during childhood is obtained to evaluate if the presence of childhood hypersensitivity to sound impedes musical experience later in life. This question is especially relevant in the context of ASD, a neurodevelopmental disorder where an atypical sensory profile present at a young age is thought to develop into less extreme behaviors at older ages (Baranek et al., 2005).

\section{Method}

\section{Participants}

This study was completed as part of a multipart experimental protocol examining emotion perception in music for which findings from separate studies have been reported elsewhere (Bhatara et al., 2010; Quintin et al., 2011). There were two experimental groups in this study. Initially, 33 adolescents with ASD were recruited: 25 from a specialized autism clinic at the Montreal Children's Hospital and 8 from a school offering special education for children with ASD. These participants were aged between 10 and 19 years and had all been diagnosed according to DSM-IV criteria at a specialized autism clinic where diagnosis is based on the expert opinion of professionals across multiple disciplines (psychiatrists, psychologists, speech language pathologists, audiologists, etc.). Parents of all participants completed the Social Responsiveness Scale (SRS, Constantino, 2002) and Social Communication Questionnaire (SCQ, Rutter, Bailey, \& Lord, 2003). Both questionnaires are commonly used validated measures of autism symptomatology (Chandler et al., 2007; Constantino et al., 2003); they were used here solely as support for the diagnosis previously established by the medical team with expertise in ASD. The questionnaires allowed us to obtain common quantitative metrics of ASD symptomatology for all participants within the ASD group and to confirm that adolescents in the control group did not show even moderate signs of ASD. From the 33 participants originally diagnosed with ASD, we excluded four because both the SRS and SCQ scores were in the normal (non-ASD) range. This corresponds to an SRS total t-score below 60 and a score below 15 on the SCQ (the SCQ provides raw scores only). One 19-year-old participant was also excluded to maintain a comparable age range between groups. For controls, we recruited 52 TD adolescents between the ages of 8 and 18 by word of mouth and from four schools in Montreal. From the 52 TD participants, nine were excluded because the SRS and SCQ scores were in the ASD range and/or because of a diagnosis of another developmental disorder. An additional eight were excluded to maintain a comparable age range between groups (ages 10-17).

Therefore, the analyses reported herein comprise 28 participants in the ASD group (23 males, 5 females) and 35 participants in the TD group (16 males, 19 females). We note that sex imbalance in the ASD group is to be expected given the higher prevalence rates of males with ASD (Fombonne, 2005). Given the higher male-tofemale ratio for the ASD group, analyses were performed for all participants and then repeated including males only.

\section{Procedure}

In addition to the SCQ and SRS described above, parents of participants completed the Salk and McGill Musical Inventory (SAMMI; Levitin et al., 2004). For the ASD group, 31 mothers and 4 fathers filled out the questionnaires. For the TD group, 22 mothers and 6 fathers filled out the questionnaires. This instrument assesses their child's history of and current musical behaviors, interest in music, and musical experience, including formal training. It includes eight demographic and developmental history questions (name, child's name, relation to child, etc.), five questions about the child's history of sound sensitivity, five questions about musical interest, six questions about (mainly emotional) responsivity to music, 15 questions about the child's musical memory, reproduction, and creativity, six questions about history of musical training (including one asking whether the child has absolute pitch), and a final free-response question asking whether the parent has any additional comments.

While the parents filled out these forms, one of the experimenters conducted a brief interview with the participants in a sound- 
isolated testing room next door to the parents' waiting room. This interview consisted of the experimenter reading from a revised version of the Queen's University Music Questionnaire (Cuddy, Balkwill, Peretz, \& Holden, 2005; Chapados \& Levitin, 2008) to assess the participants' musical training and experience as well as music listening habits and preferences. The experimenters read the questions and recorded the participant's answers verbatim. This interview lasted $\sim 5 \mathrm{~min}$. (See Appendix for questionnaire.) We also administered the Wechsler Abbreviated Scale of Intelligence (WASI) to all participants to measure IQ.

\section{Results}

There were no aspects of the questionnaires that required coding or scoring (any numbers used in the following analyses were provided by the parents, either as number of years, age, or a value on a Likert scale). We assembled all of the questionnaire and interview data and examined them to resolve any discrepancies between the reports of the parents and their children. Discrepancies relevant to the analyses performed (discrepancies in musical interest/musicality) are discussed below. ${ }^{1}$

To examine the relation between auditory sensitivity and musical variables, we performed multivariate ANOVAs or two-tailed $t$ tests comparing the two groups on interval or continuous variables and nonparametric tests on categorical variables or ordinal survey responses. We also examined musical variables' links with auditory fright/sensitivity using a logistic regression to quantify the relation, if one exists, between fright/sensitivity and music listening habits and preferences.

The first multivariate ANOVA was performed with the dependent variables of chronological age, verbal IQ, performance IQ, years of musical experience (total number of years playing one or more instruments), and number of instruments played. The effect size of group (calculated from Wilks's lambda, as recommended by Steyn \& Ellis, 2009) was $\eta^{2}=.44$. Although groups were matched for chronological age, $F_{\text {chron. age }}(1,61)=0.61, p=.44$, the participant groups differed in their IQs, with the TD group having significantly higher verbal and performance IQs, $F_{\text {verbal }}(1$, $61)=35.70, p<.001$, and $F_{\text {perf. }}(1,61)=17.30, p<.001$, respectively. The TD group reported more years of musical experience, and individuals played a greater number of instruments on average, $F_{\text {years }}(1,61)=14.00, p=.001, F_{\text {inst }}(1,61)=8.52, p=$ .005 , respectively (see Table 1 ). However, a chi-square test

Table 1

Descriptive Statistics and Group Comparisons for Participants With ASD $(\mathrm{N}=28)$ and for Participants With Typical Development (TD; $\mathrm{N}=35)$

\begin{tabular}{|c|c|c|c|c|c|}
\hline & \multicolumn{2}{|c|}{ ASD } & \multicolumn{2}{|c|}{ TD } & \multirow[b]{2}{*}{$F(1,61)$} \\
\hline & Mean & $S D$ & Mean & $S D$ & \\
\hline Age $(y r)$ & 13.4 & 1.6 & 13.8 & 2.1 & 0.61 \\
\hline Number of years training & 1.3 & 2.2 & 3.7 & 2.8 & $14.00^{*}$ \\
\hline Number of instruments & 0.8 & 0.9 & 1.6 & 1.1 & $8.52^{*}$ \\
\hline VIQ & 89 & 22 & 117 & 14 & $35.70^{*}$ \\
\hline PIQ & 95 & 17 & 110 & 13 & $17.30^{*}$ \\
\hline
\end{tabular}

Note. $\mathrm{VIQ}=$ verbal IQ $(\mathrm{WASI}) ; \mathrm{PIQ}=$ performance IQ $(\mathrm{WASI})$. ${ }^{*} p<.01$. showed that there was no group difference in response to the question "Do your parents often listen to/play music in your home?" (see Appendix question 19), ASD group: 19 yes (68\%), 9 no (32\%), TD group: 22 yes (63\%), 13 no (37\%), $\chi^{2}=0.17, p=$ .68. A chi-square test of the sex distribution between groups showed a higher male-to-female ratio in the ASD group than the TD group, $\chi^{2}=8.75, p=.003$, as expected (Fombonne, 2005).

\section{Sound Sensitivity}

We performed a chi-square test to examine our hypothesis that the ASD group would report more sensitivity to sounds. Results showed that there were more participants with ASD (18 out of 28 ; $64 \%$ ) than TD (6 out of $35 ; 17 \%$ ) whose parents reported that they showed unusual fright or sensitivity in response to certain sounds in early childhood, $\chi^{2}=14.70, p<.001$. Examples of sounds that participants had intense reactions to in childhood include loud, sudden, or unexpected sounds such as vacuum cleaners, lawn mowers, blenders, smoke detectors, sirens, horns, bells, doorbells, toilets flushing, cutlery clanking, sounds at the cinema, car radio, and crowds or large groups of people talking.

Twelve out of the 18 participants with ASD (67\%) reported a decrease in fright/sensitivity to sound over time, as did three of the six participants with TD (50\%). As previous studies have shown associations between mental age and prevalence of abnormal sensory processing, we performed logistic regressions with chronological age, years of musical training, number of instruments played, verbal IQ, performance IQ, SRS total t-score, or SCQ total raw score as possible predictors of current presence of fright/ sensitivity to sound. The only significant predictor was chronological age, $\beta=-0.65, S E=0.32, p<.05$, suggesting that sensitivity continues to decrease with age within the age range examined in this study.

\section{Musical Ability and Interest}

To examine group differences in parents' reports of their children's musical ability, we performed Mann-Whitney $U$ tests on their responses. One question asked parents to categorize their child's musical ability with six response choices ranging from "Is an excellent musician ..." to "Shows no interest" in music. Results showed that adolescents with ASD were viewed by their parents as generally having greater musical ability than adolescents in the TD group, $U=687.50, Z=3.15, p=.002$. However, responses to the question "How much interest does your child show in music-related activities?" did not differ between groups, $U=387.00, Z=-1.30, p=.20$.

Interest in music/musicality was reported similarly by parents (in the questions discussed above) and adolescent self-report (from the interview in the Appendix, question 14, "Do you consider yourself musical?") for 20 participants with ASD and 28 with TD. There were five cases in the ASD group (18\%) and seven in the

\footnotetext{
${ }^{1}$ The only frequent discrepancy (in seven cases in the ASD group, 21 in the TD group) was that the number of instruments reported differed between the parents and the children, and this was due to the parent reporting "recorder" as one of the instruments learned, and the child not reporting it. As this particular instrument was learned by almost all of the children in elementary school, but not reported by most of them, we chose not to count it.
} 
TD group (20\%) in which parents reported that their child was interested in music though the participants themselves did not. The opposite scenario, that is, participants reporting that they were interested in music while their parents said that they were not, occurred for three participants in the ASD group (11\%) and none in the TD group. Thirty-three participants in the TD group and 25 in the ASD group reported listening to music at least three to four times per week. Two-tailed $t$ tests showed that there were no differences between groups in the number of weekly hours spent listening to music, $t(60)=-1.57, p=.12$. In response to the question "At what age did your child first show interest in music?", the groups did not differ, $t(53)=1.01, p=.32$.

\section{Emotional Responsivity to Music}

In response to the question asking parents to rate the intensity of emotion expressed when their child listens to music, relative to other children (on a 7-point scale from "much less emotion" to "much more emotion"), no difference was found between groups, $U=454.50, Z=-.51, p=.61$. In addition, no difference was found in parent's reports of positive reactions to "upbeat" music (on a 7-point scale from "A little positive" to "extremely positive"), $U=405.50, Z=-1.02, p=.31$, negative reactions to "sad" music (similarly, on a 7-point scale from "a little negative" to "extremely negative"), $U=234.00, Z=.86, p=.39$, or duration of these reactions, (positive: $U=368.50, Z=-1.31, p=$ .19; negative: $U=369.50, Z=-.53, p=.60$ ). Only four parents reported negative reactions to "upbeat" music (three in the ASD group and one in the TD group), so this was not examined further. For sad music, parents reported more varied reactions (when given the choice among positive, negative, or both), but a comparison between the groups showed no significant difference in types of reactions, $U=482.00, Z=-1.25, p=.90$.

\section{Musical Interest, Memory, Reproduction, and Creativity}

When asked whether their child could reproduce music in any way (including humming and whistling, but excluding rhythmiconly reproduction), the vast majority of both parent groups responded yes: 27 of $28(96 \%)$ in the ASD group, and 32 of 35 (91\%) in the TD group. Following this were several questions about the frequency and complexity of the child's musical production and reproduction of melodies and rhythms, all asking parents to provide a rating on a 7-point scale (e.g., "How often does your child create music or songs of their own? $1=$ never; $7=$ extremely often). These were all compared using Mann-Whitney $U$ tests, but no significant differences were found.

\section{Self-Report: Favorite Musical Genres}

Adolescents' self-report of favorite musical genres was documented (see Figure 1). Both groups were found to have varied individual tastes in music. A significant difference between the groups is that five (males) out of 28 adolescents with ASD (18\%) reported classical music as their single favorite genre, while only one (female) in the TD group (3\%) reported this, $\chi^{2}=4.06, p=$ .04. There was one participant in the TD group and one in the ASD group who mentioned three or more genres of music as their favorites and included classical as one of these.

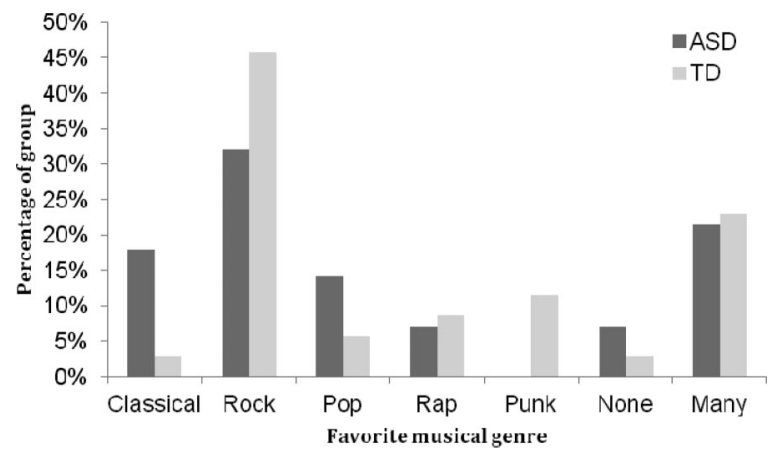

Figure 1. Favorite musical genres (percentage within each group).

\section{Accounting for the Sex Ratio}

We repeated all analyses presented within this results section including only the male participants (23 in the ASD group and 16 in the TD group), given the higher male-to-female ratio in the ASD group. The results showed the same patterns of significance. We did not repeat the analyses for only females because of the small number of female participants in the ASD group.

\section{Discussion}

This questionnaire study revealed that adolescents with ASD frequently show unusual fright or sensitivity in response to sound in early childhood, and they show this significantly more often than TD adolescents. However, this study has also shown that regardless of the sensitivities to various sounds reported during childhood, and even with fewer average years of musical experience, enjoyment of and interest for music in adolescents with ASD are similar to those of TD adolescents. Although this is a retrospective rather than a longitudinal study, it still informs us on the course of neurodevelopmental disorders such as ASD.

It is important to be cautious when using data from parent-report measures, especially retrospectively. We note that our data are consistent with many previous studies showing sensory hypersensitivities in individuals with ASD. Auditory processing abnormalities have been shown in numerous previous studies of children with ASD (e.g., Ashburner, Ziviani, \& Rodger, 2008; Baker, Lane, Angley, \& Young, 2008; Rogers et al., 2003; Tomchek \& Dunn, 2007). Cross-sectional evidence (as well as our data) suggests that sensory sensitivities decrease over time (Kern et al., 2006), although Baranek et al. (Baranek, David, Poe, Stone, \& Watson, 2006; Baranek et al., 2007) found this negative correlation to be with mental age rather than chronological age. Although there was an IQ difference between the groups in the present study, logistic regressions revealed that verbal and performance IQs did not predict fright/sensitivity to sound in ASD, and instead chronological age was negatively correlated with sensitivity. It is possible that we find this pattern because, in higher-functioning adolescents with ASD like the majority of participants in our study, mental age and chronological age are similar. However, this might not have been the case had the majority of our sample consisted of lower functioning participants with ASD. In addition, within the ASD group, no association was found between SRS total t-score and existence of sensory abnormalities. Previous research has shown 
that severity and prevalence of sensory abnormalities are related to severity of ASD symptoms in children aged 3 to 12 (Kern et al., 2007), but they do not appear to be related in adolescents and young adults (Kientz \& Dunn, 1997; Kern et al., 2007). Thus, our results showing auditory sensitivity in early childhood but not in later childhood and adolescence support and extend previously reported findings.

Our results showing typical enjoyment of music in adolescents with ASD is consistent with a previous study of adults with ASD who reported frequent use and enjoyment of music in their daily lives (Allen et al., 2009). Allen and Heaton (2010) propose that, although verbal descriptions of emotion may be hampered by alexithymia, a disorder that is characterized by a lack of insight into one's own emotions and is commonly reported in ASD, emotional enjoyment of music remains intact and could provide a powerful therapeutic tool in the treatment of this alexithymia. The results from the present study would suggest that at least the amount of exposure, liking, and emotional responsivity to music in adolescents with ASD is similar to that of TD adolescents. Further research into the emotional experience of adolescents is thus warranted to examine whether music may also be an effective therapeutic tool for children and adolescents.

The difference between groups in musical genre preference, with more adolescents in the ASD group reporting a preference for classical music over other genres, should be taken cautiously because of the small number of participants involved. In addition, because we analyzed many questionnaire items, it is possible that some differences may have arisen by chance. However, previous evidence supports the present study's results; Woody and Burns (2001) in a survey of college students showed results similar to the present study's TD group: only $1 \%$ of the students reported classical music as their favorite genre. In a study of musical listening response and habits in adults with ASD, Allen et al. (2009) found that 5 out of 12 of them (42\%) reported classical music as their favorite genre, and that this preference had developed early in life for them, which supports our findings in a younger group than that of Allen et al.

Preferred musical genre could be an interesting line of investigation because, if the effect is real, it may be due to a decreased peer influence on the ASD group. North et al.'s (2000) study of English adolescents showed that they reported listening to pop music for many reasons, such as relieving boredom, creating an image, being trendy, or pleasing their friends. However, they reported listening to classical music for only two reasons: to please parents and to please teachers. This suggests that there may be peer pressure against listening to classical music or against disclosing that one listens to classical music. This is not to say that classical music cannot provide a means for social bonding in some instances; many adolescents are involved in groups that play classical music and find social support in these groups. However, the North et al. study would suggest that its importance for social bonding outside of those specific groups is likely to be small relative to that of other genres of music. Adolescents with ASD may be less susceptible to this pressure against listening to classical music because of less of an ability to portray a particular image, or they may simply be unaware of it, which may explain why they declared classical music as their favorite while participants with TD consciously avoided doing so. Alternatively, participants with ASD might have answered that they prefer classical music to please the experimenter administering the questionnaire. Another explanation is based on speculation by Peretz (2001) who suggests that, given music's numerous social functions and the social impairments present in ASD, it would follow that people with ASD would respond differently to music than would TD listeners. In other words, they may be interested in its structural complexity rather than its emotional content. This could go toward explaining the preference that the ASD group shows for classical music, which is structurally more complex than the other specific genres reported. However, the data from the present study as well as that from Allen et al. (2009) suggest that individuals with ASD are on a whole not so different from TD individuals in their music-listening habits, and that they appreciate aspects of the music other than its structural complexity.

One aspect of our study that differentiates it from others is that our groups were not of equal size. Rather than restricting our TD group to the size of the ASD group, we chose to include as large a sample as possible in the hopes of increasing the generalizability of our results. In addition, we chose to match our groups on chronological age rather than mental age to control for the number of years of passive musical exposure.

One limitation of our study is that, when participants volunteered for the study, they were aware that it included listening to music. This may have biased our sample to include more adolescents who enjoy music than is typical. However, our goal was to compare TD adolescents with adolescents with ASD, and this bias is likely to have affected our groups equally.

A second important consideration is the difference in ratio of male to female adolescents in each group. The ASD group contained (proportionally) more male adolescents than the TD group. For adolescents and young adults, there is evidence of sex differences in music genre preference (Brittin, 1991; McCown, Keiser, Mulhearn, \& Williamson, 1997; Millar, 2008; Schwartz \& Fouts, 2003) and music listening mood-regulation strategies (Miranda \& Claes, 2009) but not in time spent listening to music (Schwartz \& Fouts, 2003). In addition, none of these studies found a sex difference specifically for classical music preference. In our sample, the one TD participant who preferred classical music was female, but all five ASD participants who preferred classical music were male. Given that there is no previous evidence of a sex bias for classical music preference, it is unlikely that the sex imbalance between groups caused this difference. However, there remains the possibility that we would have found different results if we had had the same ratio of male to female adolescents in two groups.

\section{Conclusions}

Although the parents of adolescents with ASD in our study reported more frequent hypersensitivity to sounds in early childhood than parents of TD adolescents, this hypersensitivity appeared to have no detrimental effect on the musicality of adolescents with ASD later in life. Musical involvement in everyday life seems to be similar in adolescents with ASD and TD. Although adolescents with ASD are viewed by their parents as more musical than TD adolescents, it is likely that this can be explained by parent report bias. Our findings of no significant differences between groups combined with previous research on social experiences with music in adolescence also 
suggest that music can help adolescents with ASD to have positive social experiences with their peers. For example, knowing the musical preferences of others could help adolescents with ASD identify which groups of peers provide more likely candidates for friendship. To aid them with beginning and cultivating these friendships, talking about musical preferences as a "conversation starter" could be instructed in social skills training groups.

\section{References}

Alcántara, J. I., Weisblatt, E. J. L., Moore, B. C. J., \& Bolton, P. F. (2004). Speech-in-noise perception in high-functioning individuals with autism or Asperger's syndrome. Journal of Child Psychology and Psychiatry, 45, 1107-1114. doi:10.1111/j.1469-7610.2004.t01-1-00303.x

Allen, R., Davis, R., \& Hill, E. (2013). The effects of autism and alexithymia on physiological and verbal responsiveness to music. Journal of Autism and Developmental Disorders, 43, 432-444. doi:10.1007/ s10803-012-1587-8

Allen, R., \& Heaton, P. (2010). Autism, music, and the therapeutic potential of music in alexithymia. Music Perception, 27, 251-261. doi: 10.1525/mp.2010.27.4.251

Allen, R., Hill, E., \& Heaton, P. (2009). 'Hath charms to soothe ...' An exploratory study of how high-functioning adults with ASD experience music. Autism, 13, 21-41. doi:10.1177/1362361307098511

American Psychiatric Association. (2000). Diagnostic and statistical manual of mental disorders (4th ed., text rev.). Washington, DC: American Psychiatric Association.

Ashburner, J., Ziviani, J., \& Rodger, S. (2008). Sensory processing and classroom emotional, behavioral, and educational outcomes in children with autism spectrum disorder. American Journal of Occupational Therapy, 62, 564-573. doi:10.5014/ajot.62.5.564

Baker, A. E. Z., Lane, A., Angley, M. T., \& Young, R. L. (2008). The relationship between sensory processing patterns and behavioural responsiveness in autistic disorder: A pilot study. Journal of Autism and Developmental Disorders, 38, 867-875. doi:10.1007/s10803-007-0459-0

Baranek, G. T., Boyd, B. A., Poe, M. D., David, F. J., \& Watson, L. R. (2007). Hyperresponsive sensory patterns in young children with autism, developmental delay, and typical development. American Journal on Mental Retardation, 112, 233-245. doi:10.1352/08958017(2007)112[233:HSPIYC]2.0.CO;2

Baranek, G. T., David, F. J., Poe, M. D., Stone, W. L., \& Watson, L. R. (2006). Sensory experiences questionnaire: Discriminating sensory features in young children with autism, developmental delays, and typical development. Journal of Child Psychology and Psychiatry, 47, 591601. doi:10.1111/j.1469-7610.2005.01546.x

Baranek, G. T., Parham, D. L., \& Bodfish, J. W. (2005). Sensory and motor features in autism: Assessment and intervention. In F. Volkmar, A. Klin, \& R. Paul (Eds.), Handbook of autism and pervasive developmental disorders (3rd ed., pp. 831-857). Hoboken, NJ: Wiley.

Bettison, S. (1996). The long-term effects of auditory training on children with autism. Journal of Autism and Developmental Disorders, 26, 361374. doi:10.1007/BF02172480

Bhatara, A., Babikian, T., Laugeson, E., Tachdjian, R., \& Sininger, Y. S. (2013). Impaired timing and frequency discrimination in high-functioning autism spectrum disorders. Journal of Autism and Developmental Disorders. Advance online publication. doi:10.1007/s10803-013-1778-y

Bhatara, A., Quintin, E. M., Levy, B., Bellugi, U., Fombonne, E., \& Levitin, D. J. (2010). Perception of emotion in musical performance in adolescents with autism spectrum disorders. Autism Research, 3, $214-$ 225. doi: $10.1002 /$ aur. 147

Bomba, M. D., \& Pang, E. W. (2004). Cortical auditory evoked potentials in autism: A review. International Journal of Psychophysiology, 53, 161-169. doi:10.1016/j.ijpsycho.2004.04.001
Bonnel, A., McAdams, S., Smith, B., Berthiaume, C., Bertone, A., Ciocca, V., . . . Mottron, L. (2010). Enhanced pure-tone pitch discrimination among persons with autism but not Asperger syndrome. Neuropsychologia, 48, 2465-2475. doi:10.1016/j.neuropsychologia.2010.04.020

Bonnel, A., Mottron, L., Peretz, I., Trudel, M., Gallun, E., \& Bonnel, A. M. (2003). Enhanced pitch sensitivity in individuals with autism: A signal detection analysis. Journal of Cognitive Neuroscience, 15, 226-235. doi:10.1162/089892903321208169

Boso, M., Comelli, M., Vecchi, T., Barale, F., \& Politi, P. (2009). Exploring musical taste in severely autistic subjects: Preliminary data. Annals of the New York Academy of Sciences, 1169, 332-335. doi:10.1111/j .1749-6632.2009.04853.x

Brittin, R. V. (1991). The effect of overtly categorizing music on preference for popular music styles. Journal of Research in Music Education, 39, 143-151. doi:10.2307/3344694

Bruneau, N., Bonnet-Brilhault, F., Gomot, M., Adrien, J-L., \& Barthélémy, C. (2003). Cortical auditory processing and communication in children with autism: Electrophysiological/behavioral relations. International Journal of Psychophysiology, 51, 17-25. doi:10.1016/S01678760(03)00149-1

Chandler, S., Charman, T., Baird, G., Simonoff, E., Loucas, T., Meldrum, D., . . Pickles, A. (2007). Validation of the Social Communication Questionnaire in a population cohort of children with autism spectrum disorders, Journal of the American Academy of Child and Adolescent Psychiatry, 46, 1324-1332. doi:10.1097/chi.0b013e31812f7d8d

Chapados, C., \& Levitin, D. J. (2008). Cross-modal interactions in the experience of musical performances: Physiological correlates. Cognition, 108, 639-651. doi:10.1016/j.cognition.2008.05.008

Chin, R. Y., Moran, T., \& Fenton, J. E. (2013). The otological manifestations associated with autistic spectrum disorders. International Journal of Pediatric Otorhinolaryngology, 77, 629-634. doi:10.1016/j.ijporl .2013.02.006

Constantino, J. N. (2002). The social responsiveness scale. Los Angeles, CA: Western Psychological Services.

Constantino, J. N., Davis, S. A., Todd, R. D., Schindler, M. K., Gross, M. M., Brophy, S. L., . . . Reich, W. (2003). Validation of a brief quantitative measure of autistic traits: Comparison of the social responsiveness scale with the autism diagnostic interview-revised. Journal of Autism and Developmental Disorders, 33, 427-433. doi:10.1023/A: 1025014929212

Cuddy, L. L., Balkwill, L. L., Peretz, I., \& Holden, R. R. (2005). Musical difficulties are rare: A study of "tone deafness" among university students. Annals of the New York Academy of Sciences, 1060, 311-324. doi:10.1196/annals.1360.026

Dunn, W. (1999). Short sensory profile. San Antonio, TX: The Psychological Corporation.

Fombonne, E. (2005). The changing epidemiology of autism. Journal of Applied Research in Intellectual Disabilities, 18, 281-294. doi:10.1111/ j.1468-3148.2005.00266.x

Gage, N. M., Siegel, B., Callen, M., \& Roberts, T. P. L. (2003). Cortical sound processing in children with autism disorder: An MEG investigation. Neuroreport, 14, 2047-2051. doi:10.1097/00001756-20031114000008

Gage, N. M., Siegel, B., \& Roberts, T. P. L. (2003). Cortical auditory system maturational abnormalities in children with autism disorder: An MEG investigation. Developmental Brain Research, 144, 201-209. doi: 10.1016/S0165-3806(03)00172-X

Gomot, M., Blanc, R., Clery, H., Roux, S., Barthélémy, C., \& Bruneau, N. (2011). Candidate electrophysiological endophenotypes of hyperreactivity to change in autism. Journal of Autism and Developmental Disorders, 41, 705-714. doi:10.1007/s10803-010-1091-y

Gravel, J. S., Dunn, M., Lee, W. W., \& Ellis, M. A. (2006). Peripheral audition of children on the autistic spectrum. Ear and Hearing, 27, 299-312. doi:10.1097/01.aud.0000215979.65645.22 
Heaton, P. (2003). Pitch memory, labelling and disembedding in autism. Journal of Child Psychology and Psychiatry, 44, 543-551. doi:10.1111/ $1469-7610.00143$

Heaton, P. (2005). Interval and contour processing in autism. Journal of Autism and Developmental Disorders, 35, 787-793. doi:10.1007/ s10803-005-0024-7

Heaton, P., Allen, R., Williams, K., Cummins, O., \& Happé, F. (2008). Do social and cognitive deficits curtail musical understanding? Evidence from autism and Down syndrome. British Journal of Developmental Psychology, 26, 171-182. doi:10.1348/026151007X206776

Heaton, P., Hermelin, B., \& Pring, L. (1999). Can children with autistic spectrum disorders perceive affect in music? An experimental investigation. Psychological Medicine, 29, 1405-1410. doi:10.1017/ S0033291799001221

Kanner, L. (1943). Autistic disturbances of affective contact. Nervous Child, 2, 217-230.

Kern, J. K., Trivedi, M. H., Garver, C. R., Grannemann, B. D., Andrews, A. A., Savla, J. S., . . Schroeder, J. L. (2006). The pattern of sensory processing abnormalities in autism. Autism, 10, 480-494. doi:10.1177/ 1362361306066564

Kern, J. K., Trivedi, M. H., Grannemann, B. D., Garver, C. R., Johnson, D. G., Andrews, A. A., . . S Schroeder, J. L. (2007). Sensory correlations in autism. Autism, 11(2), 123-134. doi:10.1177/1362361307075702

Khalfa, S., Bruneau, N., Rogé, B., Georgieff, N., Veuillet, E., Adrien, J. L., . . Collet, L. (2004). Increased perception of loudness in autism. Hearing Research, 198, 87-92. doi:10.1016/j.heares.2004.07.006

Khalfa, S., Dubal, S., Veuillet, E., Perez-Diaz, F., Jouvent, R., \& Collet, L. (2000). Psychometric normalization of a hyperacusis questionnaire. Journal for Otorhinolaryngology, Head \& Neck Surgery, 64, 436-442. doi:10.1159/000067570

Kientz, M. A., \& Dunn, W. (1997). A comparison of the performance of children with and without autism on the Sensory Profile. American Journal of Occupational Therapy, 51, 530-537. doi:10.5014/ajot.51.7 .530

Klin, A. (1993). Auditory brainstem responses in autism: Brainstem dysfunction or peripheral hearing loss? Journal of Autism and Developmental Disorders, 23, 15-35. doi:10.1007/BF01066416

Konstantareas, M. M., \& Homatidis, S. (1987). Brief report: Ear infections in autistic and normal children. Journal of Autism and Developmental Disorders, 17, 585-594. doi:10.1007/BF01486973

Kulesza, R. J., \& Mangunay, K. (2008). Morphological features of the medial superior olive in autism. Brain Research, 1200, 132-137. doi: 10.1016/j.brainres.2008.01.009

Leekam, S. R., Nieto, C., Libby, S. J., Wing, L., \& Gould, J. (2007). Describing the sensory abnormalities of children and adults with autism. Journal of Autism and Developmental Disorders, 37(5), 894-910. doi: 10.1007/s10803-006-0218-7

Levitin, D. J., Cole, K., Chiles, M., Lai, Z., Lincoln, A., \& Bellugi, U. (2004). Characterizing the musical phenotype in individuals with Williams syndrome. Child Neuropsychology, 10, 223-247. doi:10.1080/ 09297040490909288

Levitin, D. J., Cole, K., Lincoln, A., \& Bellugi, U. (2005). Aversion, awareness, and attraction: Investigating claims of hyperacusis in the Williams syndrome phenotype. Journal of Child Psychology and Psychiatry, 46, 514-523. doi:10.1111/j.1469-7610.2004.00376.x

McCown, W., Keiser, R., Mulhearn, S., \& Williamson, D. (1997). The role of personality and gender in preference for exaggerated bass in music. Personality and Individual Differences, 23, 543-547. doi:10.1016/ S0191-8869(97)00085-8

McIntosh, D. N., Miller, L. J., \& Shyu, V. (1999). Development and validation of the short sensory profile. In W. Dunn (Ed.), Sensory profile: Examiner's manual. San Antonio, TX: The Psychological Corporation.
Millar, B. (2008). Selective hearing: Gender bias in the music preferences of young adults. Psychology of Music, 36, 429-445. doi:10.1177/ 0305735607086043

Miranda, D., \& Claes, M. (2009). Music listening, coping, peer affiliation and depression in adolescence. Psychology of Music, 37, 215-233. doi: $10.1177 / 0305735608097245$

Mottron, L., Peretz, I., \& Ménard, E. (2000). Local and global processing of music in high-functioning persons with autism: Beyond central coherence? Journal of Child Psychology and Psychiatry, 41, 1057-1065. doi:10.1111/1469-7610.00693

North, A. C., \& Hargreaves, D. J. (1999). Music and adolescent identity. Music Education Research, 1, 75-92. doi:10.1080/1461380990010107

North, A. C., Hargreaves, D. J., \& O'Neill, S. A. (2000). The importance of music to adolescents. British Journal of Educational Psychology, 70 (Pt. 2), 255-272. doi:10.1348/000709900158083

Peretz, I. (2001). Listen to the brain: A biological perspective on musical emotions. In P. Juslin, \& J. A. Sloboda (Eds.), Music and Emotion: Theory and Research (pp. 105-134). New York: Oxford University Press.

Plaisted, K., Saksida, L., Alcantara, J., \& Weisblatt, E. (2003). Towards an understanding of the mechanisms of weak central coherence effects: Experiments in visual configural learning and auditory perception. Philosophical Transactions of the Royal Society of London B: Biological Sciences, 358, 375-386. doi:10.1098/rstb.2002.1211

Quintin, E. M., Bhatara, A., Poissant, H., Fombonne, E., \& Levitin, D. J. (2011). Emotion perception in music in high-functioning adolescents with autism spectrum disorders. Journal of Autism and Developmental Disorders, 41, 1240-1255. doi:10.1007/s10803-010-1146-0

Rimland, B., \& Edelson, S. M. (1995). Brief report: A pilot study of auditory integration training in autism. Journal of Autism and Developmental Disorders, 25, 61-70. doi:10.1007/BF02178168

Rogers, S. J., Hepburn, S., \& Wehner, E. (2003). Parent reports of sensory symptoms in toddlers with autism and those with other developmenta disorders. Journal of Autism and Developmental Disorders, 33, 631642. doi:10.1023/B:JADD.0000006000.38991.a7

Rosenhall, U., Nordin, V., Brantberg, K., \& Gillberg, C. (2003). Autism and auditory brain stem responses. Ear \& Hearing, 24, 206-214. doi: 10.1097/01.AUD 0000069326.11466.7E

Rosenhall, U., Nordin, V., Sandström, M., Ahlsén, G., \& Gillberg, C. (1999). Autism and hearing loss. Journal of Autism and Developmental Disorders, 29, 349-357. doi:10.1023/A:1023022709710

Russo, N. M., Skoe, E., Trommer, B., Nicol, T. G., Zecker, S. G., Bradlow, A., \& Kraus, N. (2008). Deficient brainstem encoding of pitch in children with Autism Spectrum Disorders. Clinical Neurophysiology, 119, 1720-1731. doi:10.1016/j.clinph.2008.01.108

Rutter, M., Bailey, A., \& Lord, C. (2003). SCQ: Social Communication Questionnaire. Los Angeles, CA: Western Psychological Services.

Schwartz, K. D., \& Fouts, G. T. (2003). Music preferences, personality style, and developmental issues of adolescents. Journal of Youth and Adolescence, 32, 205-213. doi:10.1023/A:1022547520656

Selfhout, M. H. W., Branje, S. J. T., ter Bogtb, T. F. M., \& Meeus, W. H. J. (2009). The role of music preferences in early adolescents' friendship formation and stability. Journal of Adolescence, 32, 95-107. doi: 10.1016/j.adolescence.2007.11.004

Sloboda, J. A., \& O'Neill, S. A. (2001). Emotions in everyday listening to music. In P. Juslin, \& J. A. Sloboda (Eds.), Music and emotion: Theory and research (pp. 415-429). New York: Oxford University Press.

Stiegler, L. N., \& Davis, R. (2010). Understanding sound sensitivity in individuals with autism spectrum disorders. Focus on Autism and Other Developmental Disabilities, 25, 67-75. doi:10.1177/1088357610364530

Steyn, H. S., Jr, \& Ellis, S. M. (2009). Estimating an effect size in one-way multivariate analysis of variance (MANOVA). Multivariate Behavioral Research, 44, 106-129. doi:10.1080/00273170802620238 
Tharpe, A. M., Bess, F. H., Sladen, D. P., Schissel, H., Couch, S., \& Schery, T. (2006). Auditory characteristics of children with autism. Ear and Hearing, 27, 430-441. doi:10.1097/01.aud.0000224981.60575.d8

Tomchek, S. D., \& Dunn, W. (2007). Sensory processing in children with and without autism: A comparative study using the short sensory profile. American Journal of Occupational Therapy, 61, 190-200. doi:10.5014/ ajot.61.2.190
Wiggins, L. D., Robins, D. L., Bakeman, R., \& Adamson, L. B. (2009). Brief report: Sensory abnormalities as distinguishing symptoms of autism spectrum disorders in young children. Journal of Autism and Developmental Disorders, 39, 1087-1091. doi:10.1007/s10803-009-0711-x

Woody, R. H., \& Burns, K. J. (2001). Predicting music appreciation with past emotional responses to music. Journal of Research in Music Edu cation, 49, 57-70. doi:10.2307/3345810

\section{Appendix}

\section{Queen's University Music Questionnaire - Revised}

\section{Child Interview}

1. Gender: M/F Age:

2. Grade in school:

3. Are you left/right-handed?

4. Is English your first language? Yes/No

\section{Music Training}

5. Have you ever taken any music lessons?

(NOTE: ANY kind of lessons count, including high school band class)

*** If YES, complete \#6-11; if NO, Proceed to \#12

6. At what age did you start music lessons?

7. Private or group/classroom lessons?

8. What instrument(s)? How many years of training for each instrument?

9. Years of training in total:

10. Royal Conservatory Grade Level:

11. If not Royal Conservatory, what method of training?

12. If you have brothers and/or sisters, have they had music lessons?
13. Are your parents involved in music in any way (sing, play an instrument, avid listeners, etc.)

14. Do you consider yourself musical?

15. Are you currently involved in musical activities (i.e., do you currently play an instrument or sing)?

16. How often do you listen to music? (e.g., everyday for about 3 hours)

17. What type of music do you usually listen to? (e.g., classical, rock)

18. What is your favorite type of music?

19. Do your parents often listen to/play music in your home?

20. If so, what type of music?

21. To the best of your knowledge, are you tone deaf? Yes/ No/ Somewhat/ Don't know

22. To the best of your knowledge, are you an absolute pitch (perfect pitch) possessor? Yes/No/Don't know

Received June 25, 2012

Revision received May 14, 2013

Accepted June 6, 2013 